\title{
Nucleation and Growth of Anodic Electrodeposited Cerium Oxide Thin Film
}

\author{
Yumeng Yang ${ }^{1}$, Xiaoqing $\mathrm{Du}^{1}$, Chenxi $\mathrm{Yi}^{1}$, Jiao Liu ${ }^{2}$, Zhao Zhang ${ }^{1, *}$ \\ ${ }^{1}$ Department of Chemistry, Zhejiang University, Hangzhou, Zhejiang 310027, China \\ ${ }^{2}$ College of Chemistry and Chemical Engineering, Hunan University, Changsha, Hunan, 410082, \\ China \\ *E-mail: zhangzhao@zjuem.zju.edu.cn
}

doi: $10.20964 / 2017.06 .04$

Received: 1 March 2017 / Accepted: 29 March 2017 / Published: 12 May 2017

\begin{abstract}
Cyclic voltammetry, chronoamperometry in conjunction with scanning electron microscopy and atomic force microscopy techniques have been performed to study the anodic electrodeposition behavior of ceria films onto 316L stainless steel substrate. Results show that the deposition process of ceria is controlled by diffusion under our experimental conditions. The dominated nucleation and growth mechanism for $\mathrm{CeO}_{2}$ deposition transforms from two-dimensional (2D) to three-dimensional (3D) with increasing the deposition time, and 3D process starts prior to the completion of 2D layers. The poor conductivity of the preformed $\mathrm{CeO}_{2}$ film causes the high deposition overpotential and therefore refines the grain size of $\mathrm{CeO}_{2}$ particles.
\end{abstract}

Keywords: Anodic electrodeposition; Ceria thin films; Nucleation and growth mechanism

\section{FULL TEXT}

(C) 2017 The Authors. Published by ESG (www.electrochemsci.org). This article is an open access article distributed under the terms and conditions of the Creative Commons Attribution license (http://creativecommons.org/licenses/by/4.0/). 